\title{
LINGUAGEM, CONHECIMENTO E ORIGEM: SOBRE A IDEIA DE APRESENTAÇÃO (DARSTELLUNG) EM WALTER BENJAMIN
}

Naiara Barrozo

\begin{abstract}
RESUMO
O artigo busca discutir a ideia de apresentação (Darstellung) no pensamento de Walter Benjamin a partir das discussões sobre conhecimento, saber e linguagem expostas em textos como "Sobre o programa de uma filosofia futura" (1917), "Sobre a linguagem em geral e a linguagem dos homens" (1916), e sobre a ideia de origem presente no prefácio epistemo-crítico de sua tese de livre docência Origem do Drama Barroco Alemão (1928).
\end{abstract}

Palavras-chave: Apresentação. Benjamin. Linguagem. Origem. Conhecimento

\section{LANGUAGE, KNOWLEDGE AND ORIGIN ABOUT THE BENJAMIN'S IDEA OF DARSTELLUNG}

\begin{abstract}
This paper aims to discuss the Benjamin's concept of exposition (Darstellung). It will take in consideration the discussions about knowledge and language exposed in texts as "On the program of the coming philosophy" (1917), "On language as such and on the language of man" (1916), and about the idea of origin, presented at the introduction of The Origin of German Tragic Drama (1928).
\end{abstract}

Key-words: Exposition. Benjamin. Language. Origin. Knowledge

\section{Introdução}

A necessidade de reformulação do modo de conhecer aparece em Benjamin desde seus textos de juventude escritos na década de 1910. Neles, é estabelecida uma relação entre experiência (Erfahrung), conhecimento (Erkenntnis/ Wissen) ${ }^{1}$ e linguagem (Sprache). No contexto do ensaio "Sobre o

\footnotetext{
${ }^{1}$ No prefácio do texto sobre a Origem do Drama Barroco Alemão, Benjamin apresenta uma distinção entre estes termos que não está presente nos textos do período a que me detive neste ponto. No prefácio, o conhecimento (Erkenntnis) está diretamente relacionado à filosofia Doutoranda em Teoria da Literatura no Programa de Pós-Graduação em Letras da UERJ, mestre em Filosofia (PFI-UFF), bacharel em Filosofia (UFF) e em Letras (UERJ). Bolsista CNPq. Brasileira, reside no Rio de Janeiro. E-mail: naiara.barrozo@gmail.com
} 
programa de uma filosofia futura", de 1917, a necessidade de reformulação do conhecimento aparece como modo de possibilitar a reformulação do conceito de experiência kantiano, que para Benjamin consistia em um conceito que se restringia à concepção de experiência como experiência científica. Neste ensaio impõe-se para ele como tarefa da filosofia a exigência de ser capaz de "dentro do marco da tipologia kantiana, fundar, nos termos de uma teoria do conhecimento, um conceito mais elevado de experiência". (BENJAMIN, 2000, 182. Tradução minha)

É importante lembrar, como ressalta Cláudia Castro em seu texto "Na magia da linguagem", que a proposta benjaminiana da superação do primado científico não passa por uma retomada de qualquer modelo metafísico prékantiano, como se pode pensar. O que se quer é encontrar o novo, aquilo que a história ainda não viu. Podemos apontar dois elementos constitutivos do fundamento deste novo. Um deles é o elemento religioso/teológico. O outro elemento, aquele no qual iremos nos deter, aparece apenas no final do ensaio de Benjamin. Ele é a linguagem. A superação só pode se realizar quando os pensadores forem capazes de reconhecer que o conhecimento filosófico, e, em última instância, a própria filosofia, acontecem na linguagem, e só tem expressão na língua e nunca em formas e números. O projeto da filosofia futura de Benjamin tem como pressuposto fundamental a ideia de que o conhecimento é essencialmente linguístico. O pensamento sobre essa essência, diz o jovem filósofo, será capaz de criar um conceito de experiência correspondente que irá se relacionar com âmbitos renegados pelo sistema kantiano, como é o caso da religião.

Ao afirmar a centralidade da Sprache para o conhecimento filosófico, Benjamin refere-se textualmente a Hamann. Filólogo e amigo de Kant, conhecido como figura irracionalista do romantismo alemão, ele teria sido o primeiro leitor das críticas kantianas a apontar a deficiência do sistema que ignora a essência linguística do conhecimento. Segundo Cláudia Castro, Hamann se opunha à

sistemática, pensada more geometrico, enquanto o saber (Wissen) se relaciona com a filosofia pensada como exercício de auto-apresentação da verdade na materialidade linguística da forma do tratado, contraposta ao sistema.

Doutoranda em Teoria da Literatura no Programa de Pós-Graduação em Letras da UERJ, mestre em Filosofia (PFI-UFF), bacharel em Filosofia (UFF) e em Letras (UERJ). Bolsista CNPq. Brasileira, reside no Rio de Janeiro. E-mail: naiara.barrozo@gmail.com 
dualidade sensibilidade-intelectualidade imposta por Kant. Esta dicotomia bloquearia nossa compreensão da linguagem como o lugar real de encontro entre esses dois aparentes polos. Cotidianamente a linguagem é sempre sensível e intelectiva ao mesmo tempo. Castro afirma que, nesse sentido, ao invés de operar pela prévia secção, o conhecimento deveria partir de uma reflexão sobre seu caráter linguístico, o que implicaria recuperar uma experiência cotidiana mais fundamental. Na esteira de Hamann, a comentadora afirma que essa experiência de linguagem talvez fosse capaz de transformar a realidade experimentada em conteúdo espiritual. Assim talvez ela pudesse enriquecer a relação com as coisas do mundo que se apresentariam com maior plenitude, não mutiladas pelo entendimento, assim como enriquecer a própria noção de experiência tal como Kant a entendia.

A concepção de linguagem/ língua (Sprache) que permite a construção de um conceito ampliado parece ser aquela apresentada por Benjamin alguns anos antes, em 1916, em um ensaio intitulado "Sobre a linguagem em geral e a linguagem dos homens". As formulações presentes nesse texto são fundamentais no pensamento do filósofo, reaparecendo em muitos momentos posteriores da obra benjaminiana. Elas ressurgem principalmente no prefácio epistemo-crítico do livro sobre o drama barroco alemão, atreladas à noção de apresentação da verdade (Darstellung). A ideia de que parto aqui é a de que a noção de apresentação é, de certo modo, o fruto do despertar de Benjamin para a necessidade do engendramento de uma transformação do projeto filosófico moderno, constituindo assim um elemento central a partir do qual podemos observar uma afinidade entre temas importantes para o seu pensamento, tais como o tema da linguagem, do conhecimento, do saber, da origem, da crítica literária, e da história. O movimento a que me proponho aqui é o de partir da constelação formada por esses elementos para tentar observar de que modo a ideia de apresentação se constitui.

Se, como diz Benjamin em Origem do Drama Barroco Alemão, a verdade se apresenta na materialidade das línguas particulares, é preciso, antes de tudo, compreender os aspectos centrais da filosofia da linguagem benjaminiana, que está exposta no ensaio de juventude mencionado. Nele, Benjamin irá oferecer 
uma duplicação do conceito de linguagem, que compreenderá uma linguagem não-comunicativa, a linguagem em que a verdade se expõe. Esclarecidas noções como a de nomeação adâmica e palavra, proponho que nos voltemos para a dinâmica na qual a apresentação está inscrita e para a forma escrita com a qual ela se vincula. Para isso, quero apresentar as noções de tratado e de origem (Ursprung).

\section{A linguagem do conhecimento apresentativo ou estético}

No ensaio sobre a linguagem, Benjamin apresenta o conceito de Sprache inicialmente como sendo aquele que designa o princípio que permite a comunicação de conteúdos espirituais humanos nos mais diferentes domínios, como, por exemplo, o direito e a arte. Esta linguagem/língua comunica-se pela palavra. Mas não é apenas a essência espiritual do homem que a linguagem comunica. Para Benjamin, tudo o que existe, seja animado ou inanimado, comunica seu conteúdo espiritual, e, por isso, tudo se relaciona necessariamente com a linguagem.

Esta concepção parece estar atrelada a um modo de se relacionar com a linguagem comum aos povos cuja língua não trabalha com a distinção língualinguagem, como é o caso da alemã e a inglesa. No alemão, Sprache, e, no inglês, language, designam ao mesmo tempo os dois termos que distinguimos em língua portuguesa. Como explicita a nota de Jeanne Marie Gagnebin inserida na tradução de Susana Kampff Lages, apesar de a língua alemã trabalhar com a noção de linguagem como algo próprio do homem, como algo que o distingue dos outros animais, existe nela a concepção de que na base dessa linguagem humana, das palavras, há uma linguagem que Gagnebin caracteriza como sendo uma função expressiva geral ${ }^{2}$. Esta concepção de linguagem fundamental é o que permite referir-se literalmente à linguagem dos animais e à linguagem da pintura ou da música, por exemplo. Para a comentadora, a própria língua alemã

\footnotetext{
${ }^{2}$ C.f.: GAGNEBIN, Jeanne Marie. Nota à tradução brasileira de BENJAMIN, Walter. "Sobre a linguagem em geral e a linguagem dos homens". In: Escritos sobre mito e linguagem. São Paulo: Editora 34, 2011, 49-50.
}

Doutoranda em Teoria da Literatura no Programa de Pós-Graduação em Letras da UERJ, mestre em Filosofia (PFI-UFF), bacharel em Filosofia (UFF) e em Letras (UERJ). Bolsista CNPq. Brasileira, reside no Rio de Janeiro. E-mail: naiara.barrozo@gmail.com 
tende a instigar as indagações sobre os vínculos entre essas 'linguagens' e a 'linguagem humana'.

Talvez retomando esse aspecto inerente à sua língua particular, o termo linguagem ganha no ensaio de Benjamin um sentido mais geral, passando a designar aquilo que permite a comunicação dos conteúdos espirituais de tudo o que existe; o princípio que permite o expressar-se de tudo o que é. Nesse sentido, em última instância, a expressão, tendo como princípio a linguagem, é ela mesma linguagem.

A precisão daquilo a que Benjamin pretende se referir ao fazer uso da palavra expressão se faz em uma contraposição ao modo como o termo é entendido por uma compreensão da língua que a vê como algo através do qual expressamos um conteúdo. Mais precisamente, a precisão é feita na distinção da essência espiritual com o qual cada concepção se relaciona. Quem vê uma língua como algo que serve de meio, como instrumento com fins comunicativos, tende a pensar que ela seria a manifestação imediata da essência espiritual daquilo que transmite como seu conteúdo. Para Benjamin, os partidários deste pensamento acabam por confundir a essência espiritual daquilo que pensam ser transmitido por meio da língua, da própria coisa, com a própria língua. Em termos práticos, trata-se em última instância de pensar que uma coisa com a qual nos relacionamos sensivelmente no mundo pode ser totalmente apreendida e comunicada por meio de uma língua particular, como o português ou o alemão, por exemplo; de pensar que quando descrevemos uma fotografia tudo o que colocamos em palavras é quase como se fosse, ou é, supostamente, de fato, a própria coisa que se mostrou a nós, que nada escapa. Confunde-se, portanto, a essência espiritual da coisa com a língua através da qual ela é transmitida.

Para Benjamin, ser capaz de diferenciar essas essências tradicionalmente tomadas pela identidade é fundamental para que se consiga fazer qualquer consideração teórica sobre a linguagem.

Ele aponta para outra relação com a essência espiritual a partir da apresentação de uma forma distinta de se compreender a língua. Benjamin afirma que também é possível considerá-la de outro modo, a saber: como 
"expressão imediata daquilo que se comunica dentro dela" (BENJAMIN, 2011, $51)$.

A concepção de linguagem para a qual Benjamin aponta entende a comunicação, portanto, como ação reflexiva. O que comunica engendra e sofre a ação do comunicar, comunica a si mesmo. Esse que age reflexivamente, o se da definição, é uma essência espiritual. A essência espiritual age dentro da língua. Não existe comunicação de conteúdo através da língua, mas em seu interior. O processo é interno à linguagem. De certa forma, a essência espiritual de uma coisa existe dentro da língua, mas não se confunde com ela; existe coexistindo com ela.

Esta comunicação reflexiva acontece no ponto em que a essência espiritual é identificável à essência linguística, ou seja, naquilo que nela há de comunicável. Para entender isso, é preciso saber que para Benjamin a essência espiritual de uma coisa tem ela mesma uma essência linguística. A essência espiritual se identifica à essência linguística naquilo que a possibilita comunicarse. Fazendo uso de uma imagem, é como se tivéssemos dois "objetos" - na falta de um vocábulo mais específico - dispostos como duas bonecas russas. A maior é a essência espiritual das coisas, a menor, que fica necessariamente dentro da essência espiritual, é a essência linguística. O que existe no espaço entre a essência espiritual e a essência linguística não se comunica, não participa da linguagem. Mas a boneca menor é composta de uma substância que é idêntica à de uma coisa externa, na qual ambas estão imersas. Essa coisa externa é a Sprache. O que nos é mais perceptível dos três elementos, a linguagem, é a manifestação mais clara da essência linguística da essência espiritual das coisas. Não é preciso que nada faça a mediação entre os dois elementos, porque eles estão de certo modo essencialmente ligados - são essencialmente o mesmo. É por isso que, como afirma Benjamin, "toda linguagem comunica-se a si mesma” (BENJAMIN, 2011, 53). Imersas nessa relação, as coisas da natureza manifestam suas existências. Podemos pensar que a manifestação da existência de uma coisa nunca é totalmente absoluta, mas é sempre absoluta naquilo que ela tem de manifestável, ou seja, naquilo que nela é língua. Tudo é o que é 
possível ser na língua, na linguagem. Não se trata de pensar as coisas em si, mas de pensar as coisas em suas línguas.

A definição segundo a qual "a essência linguística das coisas é sua linguagem" (Das sprachliche Wesen der Dinge ist ihre Sprache) (BENJAMIN, 2011, 53) tende a reforçar dois importantes aspectos da linguagem resguardados no duplo sentido que o verbo sein abriga. O ist marca ao mesmo tempo aquilo que a essência é e o lugar em que ela se encontra. Este caráter dúbio é explicitado por Benjamin no trecho no qual afirma que

aquilo que é comunicável em uma essência espiritual é aquilo no que ela se comunica; o que quer dizer que toda língua se comunica a si mesma. Ou melhor: toda língua se comunica em si mesma; ela é, no sentido mais puro, o meio [Medium] da comunicação (BENJAMIN, 2011, 53).

O termo Medium se opõe a Mittel, ou seja, a noção de língua como meio instrumental. Sendo Medium a língua para Benjamin é matéria, ambiente e modo da comunicação espiritual. Esta língua tem duas características fundamentais: ela é mágica e infinita. O que constitui sua magia é a imediaticidade que vimos acima. Sua infinitude, por sua vez, se deve ao fato de que o único limitador daquilo que se comunica na língua é o que é comunicável de uma coisa. Não se pode medir ou limitar nada comunicado a partir do exterior da língua, ou seja, ela é imensurável, ilimitada, e, portanto, infinita.

\section{A linguagem divina e a linguagem dos homens}

Todo o dito até agora foi referente à linguagem em geral. A linguagem dos homens é diferente. O homem se caracteriza por comunicar absolutamente sua essência espiritual. Isso é possível porque para Benjamin toda sua essência espiritual é linguagem - língua. Na comunicação da essência espiritual do homem comunica-se na língua a própria língua. Benjamin dirá mais: comunicase a pura e simples comunicabilidade:

\footnotetext{
Não há um conteúdo na língua, ou da linguagem; enquanto comunicação a linguagem comunica uma essência espiritual, isto é, uma comunicabilidade pura e simples. (BENJAMIN, 2011, 58)
}

Doutoranda em Teoria da Literatura no Programa de Pós-Graduação em Letras da UERJ, mestre em Filosofia (PFI-UFF), bacharel em Filosofia (UFF) e em Letras (UERJ). Bolsista CNPq. Brasileira, reside no Rio de Janeiro. E-mail: naiara.barrozo@gmail.com 
A essência espiritual do homem e a língua do homem comunicam-se em palavras, em nomes - não por meio das palavras; comunicam-se nomeando as outras coisas. Para essa concepção, a palavra não é uma forma de transmitir a coisa para outro ser humano. A palavra não está imersa em uma relação que acontece entre os homens através da língua, mas entre o homem e as coisas e o homem e Deus na linguagem. Por um lado, as coisas comunicam-se aos homens - basta lembrar que a linguagem é a manifestação mais perceptível a nós da essência linguística das coisas; por outro lado, diz Benjamin, os homens se comunicam a Deus.

A referência a Deus introduz no texto a dimensão teológica, tão presente no pensamento de Benjamin. Em seu artigo sobre "Teologia e Messianismo no pensamento de Walter Benjamin", Gagnebin propõe um modo de se interpretar a figura de Deus no pensamento do filósofo alemão. Para ela, dizer Deus é uma forma de dizer aquilo que é insondável, indizível ${ }^{3}$. Ele se relaciona à tentativa de descrever o objeto e de, na impossibilidade dessa definição, ser obrigado a inventar novas figuras e novos sentidos para ele. Esta capacidade de reinvenção produzida pelo indizível a que Gagnebin se refere é, em última instância, exercitar a cada momento aquela que Benjamin acredita ser a função verdadeiramente essencial da linguagem humana: a de nomear.

O conceito de nome pode ser mais bem compreendido a partir da análise profana que Benjamin faz do livro do Gênesis. Como afirma o filósofo, esta referência não tem como finalidade apresentar uma interpretação da Bíblia ou afirmá-la como verdade revelada. O objetivo é o de elucidar a natureza da linguagem humana.

De acordo com o Gênesis, Deus teria criado as coisas e o homem. As coisas foram criadas por meio da palavra. O homem não. As descrições das criações das coisas do mundo começam sempre enfatizando o caráter criativo da palavra e terminam com uma nomeação. Observemos, por exemplo, os versículos 1, 3-5: "Deus disse: Haja luz, e houve luz. Deus viu que a luz era boa; e Deus separou a luz e as trevas. Deus chamou à luz "dia", e às trevas "noite".

\footnotetext{
${ }^{3}$ Sobre a relação entre teologia e religião, c.f.: GAGNEBIN, 1999, 200.
} 
Houve uma tarde e uma manhã: primeiro dia" (BIBLIA, 2016, 33). Na esteira de Benjamin, vemos no início desse trecho a afirmação da (oni) potência criadora da linguagem divina. Na criação da luz, palavra e nome são o mesmo. O nome luz transforma a potência da linguagem em ato. No momento em que isso ocorre, Deus pode conhecer a luz, ver que é boa. Assim, no campo divino, a linguagem, como nome, se torna sabedoria. Nomear é criar e, em última instância, saber. 0 conhecimento da Criação é o conhecimento que acontece na linguagem. Essa vinculação conhecimento-linguagem-criação tem em seu fundamento a noção de que o nome e a palavra criadora, que na Criação são idênticos, são eles mesmos puro meio, puro Medium do conhecimento, e não meios [Mittel] de conhecimento; não servem para conhecer - são antes matéria, ambiente e modo do conhecer.

Mas isso não é tudo. Segundo Benjamin, ao final dos atos criadores divinos, a nomeação é também incorporação do criado à linguagem. É ao serem nomeadas que as coisas podem participar da linguagem. A partir disso, retomando a relação entre essências linguística e espiritual, seria talvez possível dizer que 0 ato de nomear é também o ato de instauração da essência linguística das coisas. Nesse caso, a instauração da essência linguística seria também a instauração da cognoscibilidade das coisas.

Diferentemente de como aconteceu com os outros seres do mundo, a criação do homem não se deu pela linguagem. Ele não é nomeado por Deus, mas é criado à sua imagem e semelhança. Deus atrela homem e linguagem atribuindo a sua criatura a capacidade de nomear, ou seja, de criar, saber, e de fazer com que as coisas do mundo participem da linguagem. A imagem de Deus será também dotada de uma linguagem que é imagem da linguagem divina. Nesse sentido, diz Benjamin, a afirmação de que a essência espiritual do homem é a linguagem significa dizer que a essência espiritual do homem é, em última instância, a linguagem da Criação. Isso implica dizer que sua essência espiritual se relaciona diretamente com a Criação e com o conhecimento que se faz na instauração da palavra criadora que é nome.

Se pensarmos na crítica que Benjamin faz à experiência kantiana e à crítica de Hamman, chama a atenção o fato de que o nome está atrelado a um 
tipo de conhecimento que parece acontecer num momento imediatamente anterior à separação entre os aspectos sensíveis e intelectuais da linguagem. Ele é talvez o instante que permite a experiência da experiência ampliada buscada por Benjamin, se impõe antes que o corte kantiano comece a operar (como será possível dizer adiante, antes da queda). Se aceitarmos isso, o momento por excelência da experiência ampliada seria o momento exato de inserção do ser na linguagem, ou seja, ela aconteceria sempre no primeiro instante do primeiro contato que temos com o ser, antes de começarmos a impor sobre ele nossos mecanismos dedutivos ou indutivos de classificação a fim de que possamos organizá-lo logicamente como tendemos a fazer com todo objeto a ser conhecido.

A condição de possibilidade dessa experiência ampliada é a aproximação da palavra humana da palavra divina, ou, em termos benjaminianos, da pura palavra, da palavra a que não corresponde previamente nenhum conhecimento e em que a língua não se torna conhecimento, mas é o lugar em que o conhecimento acontece. O momento em que é proferida a pura palavra é o instante em que algo é absolutamente igual a si mesmo e absolutamente diferente de tudo o que há, o momento do encontro da alteridade com a identidade absolutas.

Para Benjamin, o lugar em que homem estaria mais próximo da pura palavra seria no nome próprio: "o nome próprio é palavra de Deus em sons humanos" (BENJAMIN, 2011, 63), afirma. O momento de nomeação de uma criança, assim como o momento em que Adão nomeou à mulher Eva é o momento em que nomeamos algo até então totalmente desconhecido. Nesse sentido, o nome próprio sugere uma inversão da afirmativa de Benjamin, segundo a qual "Deus tornou as coisas cognoscíveis ao lhes dar nomes. Mas o homem só nomeia as coisas na medida que as conhece" (BENJAMIN, 2011, 61).

A aproximação acontece também em outro aspecto. O nome próprio não é só instauração da essência linguística, mas ele também insere as coisas no âmbito divino. Ao nomearmos uma criança, fazemos com que esse ser, gerado a partir do próprio homem, seja inserido no âmbito da criação divina pela linguagem.

Doutoranda em Teoria da Literatura no Programa de Pós-Graduação em Letras da UERJ, mestre em Filosofia (PFI-UFF), bacharel em Filosofia (UFF) e em Letras (UERJ). Bolsista CNPq. Brasileira, reside no Rio de Janeiro. E-mail: naiara.barrozo@gmail.com 
Por outro lado, o lugar em que o nome estaria mais distante do caráter divino seria no nome comum, na palavra humana com menor grau de divindade. Como visto no início, tudo o que existe se comunica na linguagem, na sua língua. É na palavra humana que nos relacionaríamos com a linguagem das coisas. Este pressuposto é a base para Benjamin fazer uma dupla crítica a dois modos de compreender a palavra humana. Primeiro, ele afasta um aspecto característico do que chama de concepção burguesa da linguagem, a saber: considerar a linguagem como um sistema de palavras que são signos e que se relacionam com as coisas de um modo totalmente arbitrário. É curioso notar que a concepção burguesa se identifica com o modo como a teoria do conhecimento tradicional se relaciona com a linguagem. É exatamente como sistema de palavras arbitrárias que carregam o significado, a informação, que as pesquisas de base matemático-científico percebem a linguagem. Ao denominá-las concepção burguesa, Benjamin vincula por meio da linguagem, a teoria tradicional do conhecimento com um modo de organização social: a linguagem burguesa é possível dizer, serve ao modo de conhecimento que serve à burguesia. Depois de falar da linguagem burguesa, ele afasta também aquilo que chama de concepção mística da linguagem, para a qual as coisas estão essencialmente ligadas à palavra.

A concepção benjaminiana considera que a palavra do homem, como nome comum, acontece a partir do comunicar-se das coisas ao homem em suas linguagens mudas. Na natureza, tudo o que foi criado, ou seja, todos os seres, mantém entre eles uma relação de correspondência. Isto quer dizer que tudo nela se responde. O homem olha para as coisas, as coisas respondem ao olhar humano, o homem corresponde. Imaginemos uma flor antes de ser flor. Esse olhar é como se, estando no mundo, percebêssemos e contemplássemos o ser flor da flor sem que ela fosse ainda flor - uma certa "floridade". Existia algo, apenas coisa existente, concreta, que em sua língua muda irradiava a palavra divina. Na linguagem mágica da natureza, o inominado percebido se comunicava a nós como se comunicava a tudo o que existia. Eis que um dia, metamorfoseamos em nossa língua, no som das palavras, aquilo que se comunicava na mudez da coisa criada. Para Benjamin, metamorfosear é 
traduzir. Esta afirmação passa a fazer mais sentido quando consideramos que para ele, há vários tipos de línguas que ele classifica em superiores e inferiores. Isso significa dizer que há línguas mais próximas à da Criação e mais afastadas, que se diferenciariam por serem meios, ambientes, mais ou menos densos em que a comunicação acontece. Nesse contexto, traduzir seria transformar densidades. Nas palavras de Benjamin,

a tradução é a passagem de uma língua para a outra por uma série contínua de metamorfoses. Séries contínuas de metamorfoses, e não regiões abstratas de igualdade e de similitude, é isso que a tradução percorre (BENJAMIN, 2011, 64).

Um dia, traduzimos, portanto, o que se comunicava no nome flor. E no nomear flor, a flor foi conhecida. Este conhecimento no nome é o conhecimento daquilo que se deu em um instante, no instante mesmo da nomeação. Ele é antes de tudo um conhecimento do particular que se apresenta para os homens no nome; talvez seja possível dizer, um conhecimento estético, retomando o sentido mais original da palavra aísthêsis, um conhecimento fundamentalmente sensível que se faz a partir do encontro com o ser na linguagem em que ele se comunica, sem mediação.

A tarefa que Deus atribuíra aos homens teria sido, segundo Benjamin, exatamente a de chegar ao último estágio do processo de nomeação: após traduzir o mudo em sonoro, fazer com que o nomeado se tornasse cognoscível no nome. A nomeação adâmica era capaz de fazer isso. Mas nos distanciamos dessa capacidade assim que, no episódio do pecado original, Adão conheceu o mal e o bem. A queda a que este episódio se refere é para Benjamin a queda da linguagem adâmica, do conhecimento nominal. Quando o homem (ish) e a mulher (îsha) comem o fruto que lhes permite conhecer o que é bom e mau, eles deixam o conhecimento imediato. Instaura-se uma nova forma de conhecer, cujo ponto de partida não são mais as coisas na linguagem, mas que está no exterior das coisas, no exterior da linguagem. O nome é convertido em um segundo tipo de palavra humana, aquele com o que se relaciona a concepção burguesa da linguagem, que transforma a linguagem em meio.

A leitura que Benjamin faz da queda explicita a configuração de um quadro em que se apresentam duas linguagens: a pura (reine Sprache) e a humana. A relação que estas linguagens mantém entre si é condição de possibilidade para Doutoranda em Teoria da Literatura no Programa de Pós-Graduação em Letras da UERJ, mestre em Filosofia (PFI-UFF), bacharel em Filosofia (UFF) e em Letras (UERJ). Bolsista CNPq. Brasileira, reside no Rio de Janeiro. E-mail: naiara.barrozo@gmail.com 
a própria noção de pureza. Esta dimensão relacional do conceito benjaminiano de pureza (Reinheit) será explicitada por Benjamin apenas alguns anos mais tarde. Ela é apresentada por Agamben em seu trabalho sobre o estado de exceção para esclarecer o conceito de pura violência (reine Gewalt) presente no ensaio "Para uma crítica da violência", publicado em 1921. O pensador italiano se refere a um trecho de uma carta do filósofo alemão a Ernst Shoen escrita em 1919, que diz o seguinte:

\begin{abstract}
É um erro pressupor, em algum lugar, uma pureza que consiste em si mesma e que deve ser preservada [...]. A pureza de um ser nunca é incondicionada e absoluta, é sempre subordinada a uma condição. Esta condição é diferente segundo o ser de cuja pureza se trata; mas nunca reside no próprio ser. E, outros termos, a pureza de todo ser (finito) não depende do próprio ser [...]. Para a natureza, a condição de sua pureza que se situa fora dela é a linguagem humana. (AGAMBEN, 2008, 94)
\end{abstract}

No quadro que se estabelece, a língua pura está atrelada à dimensão divina da linguagem, ou, em termos profanos, ao conhecimento que se faz na relação imediata com o ser. O surgimento da linguagem humana entendida no sentido burguês não implica o desaparecimento da língua pura, ou melhor, da possibilidade daquele tipo de conhecimento. Implica seu esquecimento. Mesmo que não nos lembremos dela, ainda seríamos capazes de nos relacionar com a linguagem pura no nome próprio. Nele, vemos a possibilidade da nomeação adâmica. $\mathrm{O}$ que acontece é que, em geral, opera-se pela linguagem da palavra humana, definida por Benjamin como a palavra em que

o nome não vivia mais intacto, aquela palavra que abandonou a língua que nomeia, a língua que conhece, pode-se dizer: abandonou sua própria magia imanente para reivindicar expressamente seu caráter mágico, de certo modo, a partir do exterior. A palavra deve comunicar alguma coisa (afora si mesma). (BENJAMIN, 2011, 67)

Um dos significados da queda é exatamente o surgimento do signo tal como Benjamin o entende, ou seja, como algo que está fora do processo de correspondência na linguagem das coisas da natureza. Podemos apontar duas consequências deste surgimento. Uma delas, colocada pelo próprio Benjamin, está na tese de que, sem a base una da linguagem pura, é gerada a condição de possibilidade para o surgimento da pluralidade das línguas particulares. A segunda está no fato de que o próprio homem, ao se retirar dessa relação dos seres na linguagem, se desvincula da natureza. Ele se torna sujeito e ela, objeto. 
Esse corte, que alude de certo modo à emergência do sujeito moderno, do pesquisador científico, que se relaciona com a natureza como um conjunto de objetos a ser dominado por meio de um método eficiente, faz com que a mudez comunicante da natureza dê lugar à mudez efetiva.

Benjamin aponta para um lugar em que a natureza ainda é ouvida. Esse lugar é a arte. Para ele, as formas artísticas estão situadas em um lugar intermediário. Elas estão entre a capacidade de ouvir e corresponder o ser e aquilo que é linguagem humana. Por isso, para compreendê-la é preciso considerar a doutrina dos signos. A relação entre a linguagem humana e o signo seria fundamental, motivo pelo que não é possível fazer filosofia da linguagem sem considerá-la. De qualquer modo, ela é o lugar em que a relação original existente entre o homem e a linguagem das coisas é ainda visível. Segundo afirma, o fundamento da poesia seria a linguagem dos nomes, e a escultura, a pintura teriam relação intrínseca com a linguagem das coisas, "línguas próprias do material".

No final da crítica e da depuração do conceito de linguagem empreendido por Benjamin, portanto, chegamos à arte e ao nome próprio - fundamentalmente palavra adâmica - como os lugares em que é possível vislumbrar elementos que permitem o engendramento de um tipo de conhecimento que é vinculado a um tipo de experiência não-científica, uma experiência irrestrita. Estes elementos são frutos de uma revinculação do homem com aquilo que nele há de divino, em outras palavras, da reestruturação de uma dimensão expressiva, nãocomunicativa, do falar humano, com o qual o homem resgata a possibilidade de uma relação ao mesmo tempo sensível e intelectual com o ser.

\section{0 tratado ou a forma filosófica do saber estético e da apresentação da verdade}

No Prefácio epistemo-crítico ao Origem do Drama Barroco Alemão, Benjamin irá impor como sendo a tarefa do filósofo a restauração do caráter nomeador da palavra. Desse modo, o filósofo deve ser aquele capaz de se relacionar com os seres não apenas de modo intelectual, como faz Descartes. 
Se ele quer conhecer, ele deve participar de uma relação ao mesmo tempo sensível e intelectual com os objetos. Mais do que isso, ele deve ser capaz de fazer uso da palavra como algo que não comunica, mas que apresenta aquilo que se mostra ao sujeito no momento em que se mostra do modo como se mostra, que não se deixa fixar como uma informação que serve de conteúdo a um signo comunicativo. Isso que se mostra e que não pode ser dito, o Ser que se apresenta materialmente em um instante e que não se presta à definição é o Ser da verdade. Restaurar o caráter nomeador da palavra é restaurar a capacidade de a palavra, de a linguagem, dizer o indefinível. Esta tarefa, contudo, só poderá ser empreendida por meio da assunção e execução de uma segunda tarefa: a filosofia deve assumir-se como apresentação (Darstellung) da verdade e não, apenas, como representação (Vorstellung) de algo que foi apreendido e fixado intelectualmente como uma ideia.

Segundo Jeanne Marie Gagnebin, em seu texto "Do conceito de Darstellung em Walter Benjamin ou verdade e beleza", a noção de exposição ou apresentação (Darstellung) diz respeito ao ato de acolher elementos oferecidos pelo objeto no pensar. Ele nada tem a ver com o ato de posição de um sujeito sobre um objeto reduzido. A noção de exposição da verdade responde a uma busca de Benjamin por resguardar uma dimensão da escrita e do pensamento filosóficos que foram deixados de lado pela filosofia moderna. Considerando o contexto geral da teoria do conhecimento, ele acredita que é preciso lembrar à filosofia que ela não se restringe a um pensamento que se configura como fundamento científico, especificamente como algo que deve apenas mediar e tornar possível um tipo específico de conhecimento. De certa forma, é uma maneira de buscar um modo de relação com a filosofia na qual ela se justifique por si, e não tenha sua existência justificada em função de outra atividade. Esta necessidade é explicitada em um trecho inicial do Prefácio, em que Benjamin diz que

se a filosofia quiser permanecer fiel à lei de sua forma, não como orientação mediadora para o conhecer, mas como exposição da verdade, então deve-se atribuir peso ao exercício desta sua forma, e não à sua antecipação dentro do sistema . (BENJAMIN, 1984, 50)

A filosofia tomada como meio para o conhecimento científico, entendida como o pensamento more geometrico, deixa de lado a esfera da verdade visada Doutoranda em Teoria da Literatura no Programa de Pós-Graduação em Letras da UERJ, mestre em Filosofia (PFI-UFF), bacharel em Filosofia (UFF) e em Letras (UERJ). Bolsista CNPq. Brasileira, reside no Rio de Janeiro. E-mail: naiara.barrozo@gmail.com 
pela linguagem. Até porque ela se relaciona com a palavra humana, com os signos, com aquilo que existe de dizível em um Ser e que, dessa forma, é passível de ser fixado conceitualmente e apreendido pelo intelecto. A capacidade de lidar com o indizível só é possibilitada pelo exercício (Übung) da exposição. O conceito de Übung pode ser tomado aqui como uma possível tradução da palavra grega askèsis, ascese, seguindo a esteira daquilo que Foucault afirma em um trecho da História da sexualidade. Ele une as noções de ensaio, desenvolvida por Adorno, e de exercício, a que Benjamin faz referência. No fragmento, que é inclusive citado por Gagnebin, o filósofo francês afirma que o ensaio - que deve ser compreendido como uma prova modificadora de si mesmo no jogo da verdade e não como uma apropriação simplificadora de outrem para fins de comunicação - é o corpo vivo da filosofia, pelo menos se esta ainda for hoje o que era outrora, isto é, uma "ascese", um exercício de si do pensar. (FOUCAULT, 1984, 15 apud GAGNEBIN, 2005, 187)

É na forma do tratado medieval que este exercício irá se fazer para Benjamin. O pensamento que se expõe na forma do tratado é um pensamento que não reconhece o método como um caminho reto, mas como desvio. Nas palavras do filósofo alemão,

método é desvio (Umweg) . Exposição como desvio - eis então o caráter metódico do tratado. Renúncia ao curso ininterrupto da intenção é sua primeira característica. Incansavelmente o pensamento começa sempre de novo, minuciosamente ele retorna à coisa mesma. (BENJAMIN, 1984, 50) ${ }^{4}$

No artigo supracitado, Gagnebin chama a atenção para o fato de que a palavra alemã utilizada por Benjamin, Umweg, promove um desvio da palavra grega methodos. Este desvio relaciona-se especificamente com o vínculo que, no contexto da teoria do conhecimento, o método mantém com a noção de caminho (Weg) reto, direção certa que deve ser seguida para encontrar a verdade. A comentadora nota que aqui este desvio constitui uma dupla renúncia. Benjamin indica abdicar do caminho reto e seguro como era o caminho postulado, por exemplo, por Descartes, colocando no lugar dele a errância. Neste sentido, ele abdica dos pressupostos metodológicos, das regras pré-

${ }^{4}$ Optei por seguir a tradução proposta por Jeanne Marie Gagnebin no artigo "Do conceito de Darstellung em Walter Benjamin ou verdade e beleza". (GAGNEBIN, 2005).

Doutoranda em Teoria da Literatura no Programa de Pós-Graduação em Letras da UERJ, mestre em Filosofia (PFI-UFF), bacharel em Filosofia (UFF) e em Letras (UERJ). Bolsista CNPq. Brasileira, reside no Rio de Janeiro. E-mail: naiara.barrozo@gmail.com 
existentes à pesquisa, que conferem segurança ao caminho. Mas a isso se liga ainda outra renúncia: o método como desvio abdica também do "curso ininterrupto da intenção", ele renuncia à vontade subjetiva do pesquisador, o que em última instância é o mesmo que dizer que ele renuncia à autoridade do sujeito. Ele faz isso em proveito de um recomeço incansável do pensamento, de um "incessante tomar fôlego", diz Gagnebin, em redor da coisa mesma. A coisa mesma se apresenta aqui como o centro ordenador e inacessível do pensar e do dizer. Essa coisa mesma corresponde, por exemplo, ao ser que se apresenta ao homem e que ele irá denominar flor. Ele o faz assim porque naquele momento em que ele se encontrou com o ser, o ser se apresentou a ele por meio de determinados elementos que se configuraram e que o homem percebeu como a "floridade". Mas esses elementos que se mostraram não são os únicos que constituem esta coisa, há outros que podem se mostrar em outro momento de encontro, e que levarão o homem a ter uma nova percepção do objeto. O fato de esta coisa mesma em sua totalidade sempre escapar é aquilo que irá fazer com que a enunciação filosófica sempre esteja ordenada em redor deste centro. Assim, o objeto irá impulsionar sempre ao mesmo tempo a linguagem e o pensamento. Gagnebin oferece dois modos de se compreender esta figura que atua por meio de sua ausência. Ela pode ser compreendida tanto se partimos da teologia negativa como se partirmos da noção de que a linguagem fundamentase em um centro indizível, de que ela é dotada de uma imanência radical que se furta à expressão. Nesta imanência mora a verdade. Se a exposição tem um método, este método deve expor esta capacidade furtiva que a constitui.

Para expor o que se furta, o tratado recorre a algumas estratégias específicas, que devem constituir o estilo filosófico: em contraste com a linearidade da cadeia de deduções cartesiana, a estrutura do texto do tratado deve ser intermitente. Ele deve ser interrompido a todo instante pelo pensador. Além disso, seus motivos devem sempre ser repetidos, ele nunca deve achar que o tematizado uma só vez foi capaz de dar conta do exposto, porque isso seria assumir que o exposto é dizível, é capturável em sua totalidade. Seria assumir, podemos dizer, o modo de relação da linguagem comunicativa de que Benjamin quer se afastar. O tratado deve também incluir em sua estrutura 
citações. De acordo Luciano Gatti, em Constelações: crítica e verdade em Benjamin e Adorno, no pensamento de Benjamin, citação é

referência à preexistência dos elementos na situação anterior, crítica da ordenação dessa situação anterior pela interrupção que a desmonta, e passagem para uma nova organização que mantém o arranjo anterior como arranjo estranhado (GATTI, 2009, 168).

Ela também se refere à insuficiência da linguagem como modo de apresentação totalizante da verdade, chamando a atenção para a verdade constitutiva dos próprios trechos citados. Sempre que uma citação é feita, a verdade do trecho se reapresenta renovada pelo encontro com os elementos do novo contexto.

Esta dinâmica de renovação é a dinâmica mesma do apresentar. O movimento próprio que ele constitui pode ser mais bem entendido se nos ativermos ao conceito de origem.

\section{0 procedimento de exposição da verdade como movimento originário, abertura e transformação}

No texto "Origem, Original, Tradução", Jeanne Marie Gagnebin se propõe a definir a noção de origem (Ursprung) contida no pensamento de Walter Benjamin. Para isto, afirma, é imprescindível partir de uma relação com o tempo que não queira apreendê-lo em uma cronologia. Mas como se caracteriza esta noção de tempo? Com que tipo de pesquisa ela se relaciona?

Para Benjamin, a origem é a base de uma pesquisa científica, em especial de uma historiografia, que não pressupõe uma causalidade linear e exterior aos eventos. Trata-se do que ele chamará nas teses "Sobre o conceito de história" de história filosófica e história materialista. A perspectiva que impulsiona esta noção fundamenta-se na concepção de que "o tempo está no objeto" (GAGNEBIN, 2009, 11) Se tomarmos como objeto de investigação um texto literário, por exemplo, o pressuposto é o de que a história e a temporalidade estão condensadas nele - o mesmo vale para se pensar em uma noção filosófica qualquer. O objeto é o lugar onde se encontram sua pré e sua pós-história. Mais do que isso, o objeto com o qual o pesquisador se relaciona se apresentará como o lugar em que o presente do pesquisador encontrará um ponto do presente que Doutoranda em Teoria da Literatura no Programa de Pós-Graduação em Letras da UERJ, mestre em Filosofia (PFI-UFF), bacharel em Filosofia (UFF) e em Letras (UERJ). Bolsista CNPq. Brasileira, reside no Rio de Janeiro. E-mail: naiara.barrozo@gmail.com 
em algum momento do passado foi resguardado no objeto, um ponto do tempo que ficou imóvel ${ }^{5}$. Este ponto do presente pode ser entendido como o instante em que determinada concepção do objeto foi fixada como "a" concepção, o modo de entendê-lo e de percebê-lo. Por isso, qualquer relação com o passado deve necessariamente partir do encontro com o objeto; os acontecimentos do passado só podem ser reencontrados por meio dele. O olhar que busca a origem deve voltar-se ou para a obra de arte ou para o evento histórico a ser analisado.

Esta visão centrada no interior do objeto estaria ligada a um dos três modelos epistemológicos a que o autor recorreu para pensar uma teoria alternativa à história mecanicista, e que fundamenta sua teoria da origem: o da historia naturalis. Este modelo corresponde a um pensamento clássico sobre a lei interna dos organismos vivos, desenvolvido com base na coleta de informações, seguida da separação e exposição dos elementos destes organismos, sem nenhuma pretensão de relacioná-los a partir de uma lógica cronológica ou de alguma outra que tivesse como pressuposto uma causalidade externa. Os objetos são os organismos vivos da filosofia de Benjamin, para a qual sua lei interna impõe-se, devendo reger, inclusive, o método a partir do qual eles serão investigados.

Segundo Gagnebin, a historia naturalis é apenas um dos três pilares que servem de modelo epistemológico à noção de origem. Mas ainda com relação a esse elemento, não se pode deixar de mencionar a influência goetheana. Vale citar aqui um trecho do livro das passagens retomado pela comentadora em que Benjamin afirma a influência do escritor no desenvolvimento dessa concepção:

\begin{abstract}
Estudando a exposição de Simmel do conceito de verdade de Goethe, ficou bem claro para mim que meu conceito de origem no livro sobre o Trauerspiel é uma transposição precisa e rigorosa deste princípio goethiano do âmbito da natureza para o da história. Origem - é o conceito de fenômeno originário [Urphänomen] extraído do contexto pagão da natureza e levado para a concepção judaica de história. (BENJAMIN, apud GAGNEBIN, 2009, 12)
\end{abstract}

Há outros dois pilares que sustentam a noção de origem que não podem ser ignorados. Um deles é a teologia judaica. Deste modelo proviria o espírito

5 C.f. Tese XIV de "Sobre o conceito de história". In: LÖWY, Michael. Walter Benjamin: aviso de incêndio. Uma leitura das teses "Sobre o conceito de história". São Paulo: Boitempo, 2010, 119.

Doutoranda em Teoria da Literatura no Programa de Pós-Graduação em Letras da UERJ, mestre em Filosofia (PFI-UFF), bacharel em Filosofia (UFF) e em Letras (UERJ). Bolsista CNPq. Brasileira, reside no Rio de Janeiro. E-mail: naiara.barrozo@gmail.com 
messiânico da filosofia do pensador, a "grande esperança religiosa e histórica afirmada na História do Exílio e da Redenção" (GAGNEBIN, 2009, 12). Este modelo seria um dos fundamentos para o projeto filosófico restaurativo de Benjamin, direcionado para a reconstrução de uma totalidade perdida. A partir destes dois primeiros fundamentos, a autora define a origem como algo constituído de um aspecto estrutural, pois ela é a lei interna de um objeto monadológico, e outro conceitual, pois ela mesma é um conceito que torna possível a salvação. Este espírito redentor está presente também no terceiro modelo adotado por Benjamin: o da filosofia platônica. Trata-se mais precisamente da doutrina platônica das ideias, "uma das mais profundas intuições da filosofia original" (GAGNEBIN, 2009, 12) A ideia é entendida por Benjamin como um modo de configuração dos elementos do objeto que apresenta uma verdade possível, e a rememoração, nesse contexto, como o meio de se alcançar uma totalidade fundadora que foi perdida.

Benjamin é bastante enfático em dois pontos que definem sua noção de ideia. O primeiro está no fato de que as ideias não são dadas no mundo dos fenômenos, o segundo na noção de que elas também não fazem parte de um mundo que pode ser descrito pela intuição intelectual, como é o caso das ideias cartesianas $^{6}$. Os conceitos de intuição e de ideia são negados porque eles pressupõem a existência de uma intenção prévia no processo de busca da verdade. Se pensarmos a intenção de um modo amplo, tomando como exemplo a teoria do conhecimento cartesiana, teremos o fato de que ela é desenvolvida em função de um objetivo final bastante específico: a reformulação da filosofia para a possibilidade de afirmação do conhecimento científico. O conhecimento científico se apresenta como fundamento intencional de toda investigação irmanada ao pensamento cartesiano, e, em última instância, ao pensamento representativo. Descartes determina o objeto, a concepção de verdade e o modo de proceder tendo em vista seu interesse de alcançar um determinado fim. Pensada de um modo específico, a intenção é a intenção específica do sujeito

\footnotetext{
${ }^{6}$ Sobre este segundo ponto, Benjamin afirma: "A essência das ideias não pode ser pensada como objeto de nenhum tipo de intuição, nem mesmo da intelectual". C.f. BENJAMIN, Walter. Origem do Drama Barroco Alemão. São Paulo: Brasiliense, 1984, 58.
} 
quando se debruça sobre um objeto. Ela é a intenção exposta em um projeto previamente apresentado de uma pesquisa que determina de antemão o caminho que o pesquisador irá seguir na busca da verdade. Contudo, para Benjamin, uma investigação que pressuponha uma intenção nunca alcançará a verdade. Isso porque a verdade não se deixa determinar previamente por nenhuma empiria, ela é entendida, ao contrário, como uma força que determina a empiria. Essa força, por sua vez, não é dotada de qualquer atributo fenomênico. Benjamin afirma que a verdade se apresenta no nome. A força que a constitui apresenta-se linguisticamente. É este conceito de nome também que, segundo Benjamin, permite entender o mundo das ideias. As ideias são dadas na percepção primordial, anterior à fixação do sentido do objeto em signo, vinculada à capacidade nomeadora das palavras. "As ideias se dão, de forma não-intencional, no ato nomeador, e têm de ser renovadas" (BENJAMIN, 1984, 59). Neste sentido, a noção de ideia agrega o fundamento platônico da noção de origem com o fundamento teológico, que também está presente na noção de nomeação adâmica a que se remete.

A presença dupla da soteriologia no triplo fundamento apresentado por Gagnebin, inserida por meio da teologia judaica e da filosofia platônica, poderia levar o leitor a estabelecer uma aproximação da concepção de origem benjaminiana com um dos postulados em que se sustenta a noção metafísica de origem. Esta noção se define como o lugar onde está resguardada a ordem eterna que precede a história, o lugar da essência da coisa, despida de todo acidente, de tudo o que constituiria qualquer mobilidade aparente. Entretanto, basta lembrar a oposição entre gênese e origem para que esta aproximação se mostre impossível. Considerá-la deste modo seria ignorar o fato de a origem se opor exatamente a uma concepção de história que tem como base o tempo cronológico: a origem não está na cronologia, não é um começo na linha do tempo. Ela exige o encontro com a história no objeto. A rememoração, segundo Gagnebin, a única forma pela qual pode haver a redenção dos fenômenos, pressupõe o encontro com um instante do passado que só se apresenta por meio de um objeto, por estar contido nele:

Não existem, portanto, reencontros imediatos com o passado, como se este pudesse voltar no seu frescor primeiro, como se a lembrança 
pudesse agarrar uma substância, mas há um processo meditativo e reflexivo, um cuidado de fidelidade teológica e/ou política a uma promessa de realização sempre ameaçada, pois passada no duplo sentido de vergangen (passado/desaparecido). (GAGNEBIN, 2009, 14)

O caráter da salvação como promessa que nunca se cumpre talvez se mostre melhor no desdobramento de uma das definições que a autora dá à noção de origem: ela é um salto. Esta definição, por sua vez, pode ser mais bem observada se lançarmos o olhar ao processo de rememoração e ao modo como a totalização mostra-se irrealizável no momento em que se realiza.

O processo de rememoração consiste na busca no objeto por aquilo que nele serve de testemunho a uma configuração ideal. Esta procura pode ser observada a partir tanto da pesquisa da filosofia da história quanto da crítica de arte propostas por Benjamin ao longo de sua obra. Ela é a tarefa de quem reconhece a necessidade do conhecimento estético. Em ambas as práticas, o pesquisador reconhece a necessidade do encontro com a materialidade do objeto. No caso da obra de arte, o crítico considera a realidade interna da obra que pretende criticar, atentando para aquilo que constitui a singularidade do fenômeno, ou seja, para características singulares que aparecem como seus elementos extremos que escapam a qualquer tentativa de classificação. Isso é explícito, por exemplo, no caso de toda a obra de arte que funda um gênero novo. Se comparada às obras conhecidas, ela é pura alteridade, não se encaixa em qualquer classificação e por isso engendra a necessidade do novo. Segundo Gagnebin, nestes elementos extremos estão os indícios de outra configuração ideal. Mas o estabelecimento desta configuração só será possível por meio dos conceitos, que quebram o fenômeno, dissecando seus elementos.

Não se trata de usar o conceito a fim de configurar uma nova estrutura rígida que se pretenda morada final da verdade. No contexto do prefácio epistemo-crítico, inclusive, o conceito não é a rede que ajuda o pensamento científico da filosofia a reter a verdade, tomar posse dela, conhecê-la, após seguir a coerência indutiva ou dedutiva de um sistema sem lacunas. Para Benjamin, a doutrina platônica das ideias é o lugar no qual podemos ver que "o conhecimento não coincide com a verdade" (BENJAMIN, 1984, 52), antes "a verdade é uma essência não-intencional formada por ideias"(BENJAMIN, 1984, 58). A tarefa da filosofia - assim como as tarefas da crítica e da história Doutoranda em Teoria da Literatura no Programa de Pós-Graduação em Letras da UERJ, mestre em Filosofia (PFI-UFF), bacharel em Filosofia (UFF) e em Letras (UERJ). Bolsista CNPq. Brasileira, reside no Rio de Janeiro. E-mail: naiara.barrozo@gmail.com 
filosóficas - começa ao reconhecer que não é possível alcançá-la, mas apenas buscá-la, procurando perceber na constituição empírica do objeto sinais de uma nova configuração ideal. Essa configuração é o que permite à verdade se apresentar. Apenas o engendramento da nova forma torna possível alguma reapresentação. Esse é o único modo de o filósofo aproximar-se da verdade. Por isso Benjamin afirma que "é característico do texto filosófico confrontar-se, sempre de novo, com a questão da apresentação" (BENJAMIN, 1984,49).

Contudo, como as ideias não são dadas no mundo dos fenômenos, para a filosofia da apresentação os conceitos não são absolutamente dispensáveis. Elas não se relacionam diretamente com o âmbito empírico do objeto.

Os fenômenos não entram integralmente no reino das ideias em sua existência bruta, empírica, e parcialmente ilusória, mas apenas em seus elementos, que se salvam. (...) Nessa divisão, os fenômenos se subordinam aos conceitos. São eles que dissolvem as coisas em seus elementos constitutivos. As distinções conceituais só podem escapar à suspeita de serem uma sofística destrutiva se visarem à salvação dos fenômenos nas ideias. (BENJAMIN, 1984, 56)

No projeto filosófico de Benjamin, a conceitualização instaura um duplo movimento, diz Gagnebin, ela estilhaça o objeto e o reconstrói, a partir da configuração ideal dos elementos. No que concerne à pesquisa histórica, este movimento significa resgatar aquilo que no objeto escapou à ordem estabelecida pela historiografia tradicional, trazer à tona novos sentidos do fenômeno, novas relações que até então não haviam aparecido. Para a crítica de arte, o movimento aponta para o surgimento de cada novo texto literário, por exemplo, nas interpretações imanentes. Para a filosofia, o movimento aponta para a reformulação mesma de uma ideia filosófica específica.

Em cada fenômeno de origem se determina a forma com a qual uma ideia se confronta com o mundo histórico, até que ela atinja a plenitude na totalidade de sua história.(BENJAMIN, 1984, 69)

Desta maneira, como historiador, o pesquisador quebra, na pesquisa sobre o evento, a linearidade em que o tempo foi apreendido; como crítico, ele rasga a pele da massa rígida que parecia ser antes o modo de compreensão por meio do qual uma obra de arte específica se apresentava. Este rasgar corresponde em termos práticos, por exemplo, ao questionamento da interpretação canônica de um texto literário pelo surgimento de uma nova 
interpretação. Se pensarmos no pesquisador como o filósofo, é possível considerar que este movimento corresponde ao movimento de revisão de um conceito filosófico ou de uma teoria, que fixou um momento de aparição da verdade que se impôs durante algum tempo como modo de compreensão canônico de um objeto determinado.

Este salto pode ser entendido como uma explosão a partir da qual momentos privilegiados emergem e brilham como estrelas, destoando do continuum linear e homogêneo. Estes momentos devem configurar-se como constelações, participando de uma totalidade surgida nas conexões estabelecidas a partir daquilo que é próprio a cada estrela. Este salto que possibilita a totalização, diz Gagnebin, é o salto da origem. Mais que isso, ele é a própria origem:

Trata-se muito mais de designar, com a noção de Ursprung, saltos e
recortes inovadores que estilhaçam a cronologia tranquila da história
oficial, interrupções que querem também parar este tempo infinito e
indefinido, como relata a anedota dos franco-atiradores (Tese XV), que
destroem os relógios na noite da Revolução de Julho: parar o tempo
para permitir ao passado esquecido ou recalcado surgir de novo (ent-
springen, mesmo radical que Ursprung), e ser assim retomado e
resgatado no atual. (GAGNEBIN, 2009, 14)

Como salto, extensivamente, a origem, portanto, pode ser definida como um movimento de quebra, destruição, fragmentação, restituição, dispersão, reunião, construção, que acontece de dentro para fora; movimento ascensional e amplificador da coisa. Esta mobilidade promove uma nova configuração dos elementos dos objetos, e o fenômeno, reconfigurado, reapresenta-se sempre outro:

O Ursprung não é simples restauração do idêntico esquecido, mas igualmente, e de maneira inseparável, emergência do diferente. Esta estrutura paradoxal é a do instante decisivo, do Kairós. (GAGNEBIN, 2009, 10)

Deste modo, mesmo se a salvação buscada tivesse como paradigma um estágio primeiro, a origem instaura a redenção da totalidade a partir de uma abertura na história, a partir da emergência do diferente. Ela nunca leva ao mesmo, nunca permite o retorno a qualquer estágio de perfeição. Nisto consiste o que Gagnebin chama de paradoxo essencial da origem de Benjamin, que o afasta da concepção metafísica. Considerando a história, por exemplo, ela

Doutoranda em Teoria da Literatura no Programa de Pós-Graduação em Letras da UERJ, mestre em Filosofia (PFI-UFF), bacharel em Filosofia (UFF) e em Letras (UERJ). Bolsista CNPq. Brasileira, reside no Rio de Janeiro. E-mail: naiara.barrozo@gmail.com 
instaura sempre uma abertura no tempo, operando no inacabamento tanto do objeto, que sempre se oferece à restauração, quanto da história, que, ao ser rompida, é sempre renovada.

\section{CONCLUSÃO}

Neste procedimento, tanto no caso de um objeto como evento histórico, como no caso de um objeto como obra de arte específica, ou mesmo no caso de um conceito, o movimento que se promove é o de um salto cortante em uma homogeneidade. Esta homogeneidade pode ser entendida como a configuração fixa de um modo por meio do qual a verdade de um objeto se apresentou um dia. Ela é o único modo de configuração permitida pela linguagem humana. $O$ instante do corte, da explosão, é o instante em que a verdade mais uma vez aparece. Ela é o instante em que entra em jogo a dimensão adâmica da linguagem, no nome. Esta linguagem engendra a abertura porque a abertura é o modo de materialização do indizível. É o indizível da aparição da verdade, que, em última instância, permite o engendramento de uma nova configuração. $O$ momento do salto é, em termos práticos, o momento em que o homem se depara com aquilo sobre o que ele ainda não consegue dizer. A partir da imposição ao intelecto daquilo que é percebido, mas que não encontra palavras nas quais se fixar, engendra-se uma ruptura que suspende o sentido comum frente ao que se impôs o indizível. Provisoriamente o objeto é percebido pelo sujeito como uma coisa mesma. Uma coisa mesma que mostra sobre si uma verdade que não havia sido ainda mostrada. Ao que parece, o fim da abertura só é possível com o retorno à linguagem humana, com o retorno a uma nova homogeneidade cognitiva, por assim dizer. Ela será feita a partir do momento que o homem for capaz de fixar algo do que se mostrou em um signo ou em um conjunto de signos. Mas a verdade nunca poderá ser totalmente fixada. Aquilo com o que o signo se relaciona será apenas o espólio da verdade apresentada, um fotograma.

No contexto da teoria do conhecimento, a linguagem burguesa, que opera por signos, é definida como a linguagem da filosofia da representação. Isso significa dizer que a filosofia da representação opera essencialmente na 
homogeneidade. Sua estrutura mesma não permite qualquer quebra no modo de compreensão da realidade, no modo de compreensão dos seres. Ela não permite que o ser se diga de um modo distinto daquele que ele se disse algum dia ao homem.

Por outro lado, a noção de apresentação da verdade engendra a possibilidade de um pensamento que permite a produção de uma abertura no modo de percepção da realidade cotidiana, assim como no modo de compreensão dos seres que, relacionando-se uns com os outros, constroem esta realidade. Tudo aquilo que se apresenta ao homem na realidade cotidiana, mesmo que continue sendo materialmente o mesmo, a partir do movimento da origem instaurado pela tentativa de apresentação, pode se apresentar a este pensamento de modo, pelo menos, um pouco diferente. Apresentar é sempre transformar.

\section{REFERÊNCIAS}

AGAMBEN, Giorgio. Estado de exceção. Tradução: Iraci D. Poleti. São Paulo: Boitempo, 2008.

BENJAMIN, Walter. Origem do Drama Barroco Alemão. Tradução, apresentação e notas: Sérgio Paulo Rouanet. São Paulo: Brasiliense, 1984. . "Sobre a linguagem em geral e a linguagem dos homens".

In__: Escritos sobre mito e linguagem. São Paulo: Editora 34, 2011. . "Sur le programme de la philosophie qui vient". In:Oeuvres $I$.

Paris: Éditions Gallimard, 2000. . "Über Sprache überhaupt und über die Sprache des Menschen"

In_ : Gesammelte Schriften. Bd. II (Aufsätze, Essays, Vorträge).Frankfurt am Main: Suhrkamp, 1977.

BÍBLIA. Bíblia de Jerusalém. São Paulo: Editora Paulus, 2016.

CASTRO, Cláudia. "Na magia da linguagem". In__: O que nos faz pensar. №6, 1992.

FOUCAULT, Michel. Histoire de la sexualité. Paris: Gallimard, 1984. 
GAGNEBIN, Jeanne Marie. "Do conceito de Darstellung em Walter Benjamin ou verdade e beleza", KRITERION, Belo Horizonte, no 112, DEZ/ 2005, p.183-190. Disponível em o). Acessado em: 04/11/201 . "Origem, original, tradução". In__: História e Narração em Walter Benjamin. São Paulo: Perspectiva, 2009. . "Teologia e Messianismo no pensamento de W. Benjamin". In__: Estudos Avançados v. 13, no 37, 1999.

GATTI, Luciano. Constelações: crítica e verdade em Benjamin e Adorno. São Paulo: Loyola, 2009.

LÖWY, Michael. Walter Benjamin: aviso de incêndio. Uma leitura das teses “Sobre o conceito de história”. São Paulo: Boitempo, 2010. 